\title{
Doğu Akdeniz Bölgesi'ndeki mısır alanlarında Cicadellidae (Hemiptera) türlerinin belirlenmesi
}

Determination of Cicadellidae (Hemiptera) species in the maize fields in Eastern Mediterranean region of Turkey

\author{
Vahdettin AKMEŞE ${ }^{1}$ (D) Erdal SERTKAYA ${ }^{2}$ \\ ${ }^{1}$ Adana Biyolojik Mücadele Araştırma Enstitüsü Müdürlüğü, Yüreğir, Adana \\ ${ }^{2}$ Hatay Mustafa Kemal Üniversitesi, Ziraat Fakültesi, Bitki Koruma Bölümü, Antakya, Hatay.
}

MAKALE BILGISI / ARTICLE INFO

Makale tarihçesi / Article history:

DOI: $10.37908 /$ mkutbd.942002

Geliş tarihi /Received:24.05.2021

Kabul tarihi/Accepted:13.07.2021

\section{Keywords:}

Maize, leafhopper species, vector, D-Vac, Eastern Mediterranean Region.

Corresponding author: Erdal SERTKAYA

$\bowtie$ : esertkaya@mku.edu.tr

\section{ÖZET / A BSTRACT}

Aims: The aim of this study is to determine the pest species belonging to the Cicadellidae family in the first and second crop maize fields in Adana, Osmaniye, Mersin and Hatay provinces in the Eastern Mediterranean Region.

Methods and Results: This study was conducted in the main and second crop corn cultivation areas in Adana, Mersin, Osmaniye and Hatay provinces in the Eastern Mediterranean Region between 2013-2014. The samplings were absorbed for 60 seconds each by the vacuum insect machine ( $D-V a c)$ at five different points of each field. The leafhoppers were sampled in a total of 236 fields in three phenological periods as vegetative, generative and ripening in the first and second crop cultivation areas of corn plant.

Conclusions: At the end of the study, 32 species belonging to 5 subfamilies of Cicadellidae (Hemiptera) family were determined. Two of the species belong to Agalliinae, one to Dorycephalinae, one to Hecalinae, six to Typhlocybinae and 22 to Deltocephalinae. Distribution of species by provinces 23 species belonging to three subfamilies in Adana, 22 species belonging to three subfamilies in Osmaniye, 19 species belonging to three subfamilies in Mersin and 20 species belonging to five subfamilies in Hatay were determined.

Significance and Impact of the Study: Cicadellidae species identified in the study, Asymmetropteryx pictilis (Stal, 1853), Allygus provincialis (Ferrari 1882) and Cicadula (Cypherana) intermedia (Boheman, 1845) species is the first record for the fauna of Turkey. The most collected sample in the region causes swelling, gall, stunting in growth as a result of the fact that C. bipunctella is a virus vector and the chemical secretion secreted during feeding. Therefore, it is predicted that this species may cause economically important yield losses in corn in the coming years. Along with $C$. bipunctella, Circulifer haematoceps, Neoaliturus fenestratus, Psammotettix striatus species known as virus vector should also be followed and the possibilities of struggle against possible populations should be investigated in the following years. 


\section{Giriş}

Tarımsal üretimimizde tahıllar içerisinde önemli bir yeri olan mısır (Zea mays L.), eskiden çoğunlukla hayvan yemi olarak yetiştirilmesine rağmen son yıllarda bitkisel yağ olarak insan beslenmesinde, boya ve kâğıt endüstrisinde yaygın bir kullanım payına sahip olmuştur (Lodos, 1981). Akdeniz Bölgesi'nde elde edilen ürünün yüksek getirisi ve tarımının kolay olması nedeniyle uzun yıllardır geniş alanlarda mısır tarımı yapılmaktadır. Ayrıca pazar sorununun olmaması ve devlet tarafından desteklenmesi sonucu bu bölgede ana üründe son yıllarda ekiliş alanlarının artmasına neden olmuştur. Bu nedenlerden dolayı çok daha geniş alanlarda yetiştirilen mısırın ekonomik getirisinin artması, fitofag Arthropodların ürüne verdiği kayıplar önemsenmiştir (Mutlu ve ark., 2008a,b).

TÜIK'in 2018 yılı verilerine göre Türkiye'de 108.991.783 dekar tahıl üretiminin 6.388.287 da alanında mısır üretilmektedir. Doğu Akdeniz Bölgesinde (Adana, Mersin, Osmaniye ve Hatay) 1.283.646 dekar alanda mısır ekilmektedir. Ülkemizde üretilen 5.700 .000 ton mısırın 1.436.112 tonu Doğu Akdeniz Bölgesinde üretilmekte ve ortalama $1.116 \mathrm{~kg} /$ da verim alınmaktadır (Anonim, 2018).

Mısırda birçok zararlı Arthropod türü bitkinin değişik fenolojik dönemlerinde ortaya çıkarak üründe doğrudan ya da dolaylı olarak zarara ve dolayısıyla ekonomik ürün kayıplarına neden olmaktadır. Bu zararlı böcek gruplarından biri de içerisinde birçok türü barındıran yaprakpireleri (Hemiptera, Cicadellidae)'dir. Polifag ve monofag türleri olan yaprakpireleri bitki özsuyunu emerek zarar vermektedir (Mutlu ve Sertkaya, 2016). Bazı türlerin virüs ve diğer hastalık etmenlerinin vektörü olduğu, beslendiği bitkilerin iletim demetlerini tıkadıklarından köklerden yapraklara su ve besin elementi, yapraklardan ise bitkilerin diğer organlarına karbonhidrat taşınması engellendiğinden bitkilerde hastalık simptomları ortaya çıkmaktadır. Ayrıca yumurta bırakma sırasında bitkinin dokusuna zarar verdiği bilinmektedir (Oman, 1949; Bushing ve Burton, 1974; Nault, 1980). Mısırda belirlenmiş olan 60'dan fazla virüs hastalığının yaklaşık 25' inin yaprakpireleri ile taşındığı belirlenmiştir (Seifers ve Harvey, 1989). Bu zararlarından dolayı potansiyel zararlı olsalar da yaprakpireleri zaman içerisinde önemli konuma geçebilmektedirler (Lodos, 1981). Ülkemizde konu ile ilgili yapılan çalışmalar incelendiğinde, Hatay'da Solanaceae familyası üzerinde 18 (Kılıç ve Sertkaya, 2019), ışık tuzağıyla yapılan diğer bir çalışmada ise farklı kültür bitkilerinde (mısır, pamuk, sebze) 30 Cicadellidae türü tespit edilmiştir (Kaya ve Başpınar, 2019). Ege Bölgesinde mısırda Cicadellidae familyasına bağlı 17 tür belirlenmiş, bunlardan $A$. decedens ve $Z$. pullula'nın çok yaygın ve yoğun türler olduğu (Yılmaz ve ark., 2009), Konya'da Z. sohrab'ın mısırda iki döl verdiğini ve üründe \%17,7-31,9 arasında ürün kaybına neden olduğu belirlenmiştir (Alaoğlu ve ark, 2007). Diyarbakır'da ikinci ürün mısırda Cicadellidae familyasına bağı 20 türün bulunduğu ve bunlardan $A$. decedens, E. decipiens, Z. sohrab ve $P$. striatus' un önemli türler olduğu bildirilmiştir (Mutlu ve ark., 2008 a,b).

Doğu Akdeniz Bölgesinde mısır alanlarında yaprakpirelerine yönelik sadece Adana ili mısır alanlarında 1988-1991 yıllarında yapılan bir çalışmada $A$. decedens'in mısırda \%83'lük oranıyla baskın tür olduğu belirtilmiştir. $A$. decedens ve $E$. decipiens popülasyonlarının ana ürün mısırda Mayıs ayı başlarında, ikinci üründe ise Temmuz ayında en yüksek noktaya ulaştı̆̆ı bildirilmiştir (Başpınar, 1994).

Bu çalışma ile Doğu Akdeniz Bölgesinde, 2013-2014 yıllarında Adana, Mersin, Osmaniye ve Hatay illerinin ana ve ikinci ürün mısır üretim alanlarında bulunan yaprakpiresi türleri ortaya çıkarılmıştır.

\section{MATERYAL ve YÖNTEM}

\section{Materyal}

Adana, Mersin, Osmaniye ile Hatay illerindeki birinci ve ikinci ürün mısır üretim alanları, yaprakpiresi türleri ve vakumlu böcek toplama aleti (boru ağzı çapı $12 \mathrm{~cm}$, hava hacmi $720 \mathrm{~m}^{3} \mathrm{~h}^{-1}, 70 \mathrm{~m} \mathrm{~s}^{-1}$ hava emme ve üfleme hızında) çalışmanın ana materyalini oluşturmuştur. Yaprak toplama ve üfleme makinesi olarak tasarlanan OLEOMAC BW300 marka isimli alet vakumlu böcek toplama aleti olarak modifiye edilerek sürvey çalışmalarında kullanılmıştır (Anonim, 2013).

Ayrıca stereoskopik mikroskop, lup, polietilen torbalar, kurutma kâğıdı, kültür kapları, buz kabı, samur fırçalar ve diğer malzemelerden de faydalanılmıştır.

\section{Yöntem}

Çalışma 2013-2014 yıllarında Doğu Akdeniz Bölgesi'nde bulunan birinci ve ikinci ürün mısır ekim alanlarında yaprakpiresi türlerini belirlemek amacıyla yürütülmüştür. 2013 yılında 139 tarla ve 11.867 da alanda, 2014 yılında ise 97 tarla ve 7193 da alanda örneklemeler yapılmıştır. Birinci ve ikinci ürün mısırın üç fenolojik dönemde yürütülen çalışmalarda örnekleme yapılan tarla sayıları ve alanları Çizelge 1 - 4'de verilmiştir. 
Çizelge 1. Doğu Akdeniz Bölgesi ana ürün mısır ekiliş alanlarında 2013 yılında örnekleme yapılan tarla sayıları ve alanları Table 1. The number of fields and the size of all areas sampled at main maize cultivation areas in Eastern Mediterranean Region, in 2013

\begin{tabular}{lcccccccc}
\hline & \multicolumn{2}{c}{ Adana } & \multicolumn{2}{c}{ Osmaniye } & \multicolumn{2}{c}{ Mersin } & Hatay \\
\cline { 2 - 8 } Fenolojik & \multirow{2}{*}{ Dönemler } & Tarla Sayısı & Alan (da) & Tarla Sayısı & Alan (da) & Tarla Sayısı & Alan (da) & Tarla Sayısı Alan (da) \\
\hline Vejetatif & 13 & 1320 & 7 & 635 & 6 & 375 & 6 & 680 \\
Generatif & 12 & 1180 & 5 & 590 & 5 & 580 & 5 & 582 \\
Olgunlaşma & 6 & 365 & 4 & 250 & 3 & 180 & 3 & 260 \\
\hline Toplam & 31 & 2865 & 16 & 1475 & 14 & 1135 & 14 \\
\hline
\end{tabular}

Çizelge 2. Doğu Akdeniz Bölgesi II. ürün mısır ekiliş alanlarında 2013 yılında örnekleme yapılan tarla sayıları ve alanları Table 2. The number of fields and size of all areas sampled at second maize cultivation areas in Eastern Mediterranean Region, in 2013

\begin{tabular}{|c|c|c|c|c|c|c|c|c|}
\hline \multirow[b]{2}{*}{$\begin{array}{l}\text { Fenolojik } \\
\text { Dönemler }\end{array}$} & \multicolumn{2}{|c|}{ Adana } & \multicolumn{2}{|c|}{ Osmaniye } & \multicolumn{2}{|c|}{ Mersin } & \multicolumn{2}{|c|}{ Hatay } \\
\hline & Tarla Sayısı & $\begin{array}{l}\text { Alan } \\
\text { (da) }\end{array}$ & Tarla Sayısı & $\begin{array}{l}\text { Alan } \\
\text { (da) }\end{array}$ & Tarla Sayısı & Alan (da) & Tarla Sayısı & $\begin{array}{l}\text { Alan } \\
\text { (da) }\end{array}$ \\
\hline Vejetatif & 11 & 1020 & 7 & 540 & 5 & 230 & 6 & 535 \\
\hline Generatif & 8 & 780 & 4 & 260 & 4 & 165 & 5 & 340 \\
\hline Olgunlaşma & 6 & 490 & 3 & 180 & 2 & 120 & 3 & 210 \\
\hline Toplam & 25 & 2290 & 14 & 980 & 11 & 515 & 14 & 1085 \\
\hline
\end{tabular}

Çizelge 3. Doğu Akdeniz Bölgesi ana ürün mısır ekiliş alanlarında 2014 yılında örnekleme yapılan tarla sayıları ve alanları

Table 3. The number of fields and size of all areas sampled at main maize cultivation areas in Eastern Mediterranean Region, in 2014

\begin{tabular}{lccccccccc}
\hline & \multicolumn{2}{c}{ Adana } & \multicolumn{2}{c}{ Osmaniye } & \multicolumn{2}{c}{ Mersin } & \multicolumn{2}{c}{ Hatay } \\
\cline { 2 - 9 } $\begin{array}{l}\text { Fenolojik } \\
\text { Dönemler }\end{array}$ & Tarla Sayısı & Alan (da) & Tarla Sayısı & $\begin{array}{c}\text { Alan } \\
\text { (da) }\end{array}$ & Tarla Sayısı & $\begin{array}{c}\text { Alan } \\
\text { (da) }\end{array}$ & Tarla Sayısı & $\begin{array}{c}\text { Alan } \\
\text { (da) }\end{array}$ \\
\hline Vejetatif & 7 & 510 & 4 & 280 & 2 & 190 & 3 & 170 \\
Generatif & 6 & 545 & 4 & 260 & 2 & 145 & 4 & 265 \\
Olgunlaşma & 7 & 740 & 5 & 275 & 3 & 250 & 4 & 415 \\
\hline Toplam & 20 & 1795 & 13 & 815 & 7 & 585 & 11 & 850 \\
\hline
\end{tabular}

Çizelge 4. Doğu Akdeniz Bölgesi II. ürün mısır ekiliş alanlarında 2014 yılında örnekleme yapılan tarla sayıları ve alanları Table 4. The number of fields and size of all areas sampled at second maize cultivation areas in Eastern Mediterranean Region, in 2014

\begin{tabular}{|c|c|c|c|c|c|c|c|c|}
\hline \multirow[b]{2}{*}{$\begin{array}{l}\text { Fenolojik } \\
\text { Dönemler }\end{array}$} & \multicolumn{2}{|c|}{ Adana } & \multicolumn{2}{|c|}{ Osmaniye } & \multicolumn{2}{|c|}{ Mersin } & \multicolumn{2}{|c|}{ Hatay } \\
\hline & Tarla Sayısı & $\begin{array}{l}\text { Alan } \\
\text { (da) }\end{array}$ & Tarla Sayısı & $\begin{array}{l}\text { Alan } \\
\text { (da) }\end{array}$ & Tarla Sayısı & $\begin{array}{l}\text { Alan } \\
\text { (da) }\end{array}$ & Tarla Sayısı & $\begin{array}{l}\text { Alan } \\
\text { (da) }\end{array}$ \\
\hline Vejetatif & 7 & 435 & 4 & 270 & 2 & 75 & 2 & 125 \\
\hline Generatif & 6 & 560 & 4 & 280 & 3 & 215 & 3 & 230 \\
\hline Olgunlaşma & 6 & 490 & 5 & 278 & 2 & 80 & 2 & 110 \\
\hline Toplam & 19 & 1485 & 13 & 828 & 7 & 370 & 7 & 465 \\
\hline
\end{tabular}

Vakumlu Böcek Toplama Aleti ile yapılan örneklemeler mısır bitkisinin 2-4 yapraklı olduğu dönemden itibaren başlayarak vejetatif gelişme (erken helezon, orta helezon ve geç helezon), generatif (püskül ve koçan püskülü oluşumu) ve olgunluk dönemleri olmak üzere üç dönemde yapılmıştır. Sürvey çalışmalarında toplanan örnekler, üzerinde bitkinin fenolojik dönemi, örneğin alındığı yer (il, ilıçe ve Köy) ve tarih bilgilerini içeren 
etiketlerin bulunduğu nemlenmeyi önlemek için içerisine kurutma kağıdı bırakılan polietilen torbalara konularak buz kaplarında laboratuvara getirilmiştir.

Toplanan örnekler $-21^{\circ} \mathrm{C}^{\prime}$ de difrizde en az 45 dakika bekletilerek öldürülmüş ve sonra laboratuvarda ergin bireyler stereobinoküler mikroskop ile diğer böcek ve bitki parçalarından ayrılmıştır. Elde edilen bireylerden morfolojik yapısı benzer olanlar ayrılmış ve eppendorf tüplere konulup bilgi etiketleri yapıştırıldıktan sonra tanılama için koleksiyona alınmış ve konu uzmanına gönderilerek teşhis ettirilmiştir.

\section{BULGULAR ve TARTIŞMA}

Çizelge 5. Doğu Akdeniz Bölgesi I. ve II. ürün mısır alanlarında 2013-2014 yıllarında belirlenen yaprakpiresi (Hemiptera, Cicadellidae) türlerinin bulunduğu alanlar

Table 5. The areas and the leafhopper species determined at first and second maize areas in the Eastern Mediterranean Region in 2013-2014

\begin{tabular}{|c|c|c|c|c|c|c|c|c|c|c|c|c|c|}
\hline iller & \multicolumn{5}{|c|}{ Adana } & \multicolumn{3}{|c|}{ Osmaniye } & \multirow{2}{*}{$\begin{array}{c}\text { Mersin } \\
\frac{n}{\frac{n}{\sigma}} \\
\stackrel{n}{\models}\end{array}$} & \multicolumn{4}{|c|}{ Hatay } \\
\hline îlçeler & 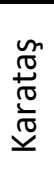 & 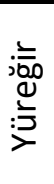 & $\frac{\frac{c}{d}}{\frac{c}{d}}$ & $\begin{array}{l}\text { ᄃ } \\
\text { N } \\
\text { O }\end{array}$ & 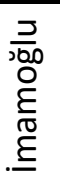 & 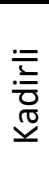 & 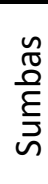 & $\begin{array}{l}\frac{0}{\pi} \\
\frac{0}{2} \\
\frac{0}{0} \\
\frac{0}{0}\end{array}$ & & 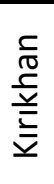 & $\begin{array}{l}\frac{\Xi}{\bar{\varepsilon}} \\
\underline{\underline{\partial}}\end{array}$ & 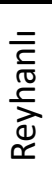 & 高 \\
\hline \multicolumn{14}{|l|}{ Türler } \\
\hline \multicolumn{14}{|l|}{ Agalliinae } \\
\hline Agallia laevis (Ribaut, 1935) & + & + & + & & + & + & + & + & + & + & & + & \\
\hline Anaceratagallia ribauti & + & & + & + & + & + & + & + & + & + & + & + & \\
\hline \multicolumn{14}{|l|}{ Dorycephalinae } \\
\hline Eupelix cuspidata (Fabricus, 1779) & & & & & & & & & & & & + & \\
\hline \multicolumn{14}{|l|}{ Hecalinae } \\
\hline Parabolocratus (Hecalus) storai (Lindberg, 1936) & & & & & & & & & & & & + & \\
\hline \multicolumn{14}{|l|}{ Typhlocybinae } \\
\hline Asymmetrasca decedens (Paoli, 1932) & + & + & + & + & + & + & + & + & + & + & + & + & + \\
\hline Asymmetropteryx pictilis (Stal, 1853) & + & + & + & + & + & + & + & + & + & + & + & + & + \\
\hline Empoasca decipiens (Paoli, 1930) & + & + & + & + & + & + & + & + & + & + & + & + & + \\
\hline Empoasca(Empoasca) vitis (Göthe,1875) & + & + & + & + & + & + & + & + & + & + & + & + & + \\
\hline Zyginidia flammigera (Geoffroy, 1785) & & & & & & & & & + & & & + & \\
\hline Zyginidia sohrab (Zachvatkin, 1947) & + & + & + & + & + & + & + & + & + & + & + & + & + \\
\hline \multicolumn{14}{|l|}{ Deltocephalinae } \\
\hline Allygus provincialis (Ferrari 1882) & & & & & + & & & & & & & & \\
\hline Balclutha hebe (Kirdaldy, 1906) & + & + & + & + & + & + & + & + & + & + & + & + & + \\
\hline Balclutha punctata (Fabricıus, 1775) & + & + & + & + & + & + & + & + & + & + & + & + & + \\
\hline Chiasmus conspurcatus (Perris, 1857) & + & & & & & & & & & & & & \\
\hline Cicadula intermedia (Boheman,1845) & & & & + & & & & & & & & & \\
\hline
\end{tabular}

Doğu Akdeniz Bölgesi I. ve II. ürün mısır ekim alanlarında 2013-2014 yıllarında yapılan sürveyler sonucunda Cicadellidae (Hemiptera) familyasına ait toplam 32 tür belirlenmiştir. Türlerden ikisi Agalliinae, biri Dorycephalinae, biri Hecalinae, altısı Typhlocybinae ve 22 adedi ise Deltocephalinae altfamilyalarına aittir. Çizelgede türlerin belirlendiği ilçelerdeki alanlar + ile işaretlenmiştir. Adana, Mersin, Hatay ve Osmaniye illerinde birinci ve ikinci ürün mısır ekim alanlarındaki yayılışları Çizelge 5'de verilmiştir. Örnekleme yapılan yerlerde ve dönemlerde toplanan Cicadellidae türlerinin bulunma oranı Şekil 1'de verilmektedir. 
Çizelge 5. (Devamı) Doğu Akdeniz Bölgesi I. ve II. ürün mısır alanlarında 2013-2014 yıllarında belirlenen yaprakpiresi türleri ve bulunduğu alanlar

Table 5. (Continued) The areas and the leafhopper species determined at first and second maize areas in the Eastern Mediterranean Region in 2013-2014

\begin{tabular}{|c|c|c|c|c|c|c|c|c|c|c|c|c|c|}
\hline iller & & & dar & & & & nan & & Mersin & & & & \\
\hline illçeler & $\begin{array}{l}\underset{\pi}{\pi} \\
\stackrel{m}{\sigma} \\
\frac{\pi}{\sigma}\end{array}$ & 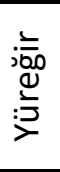 & $\frac{\frac{c}{d}}{\frac{\pi}{d}}$ & $\begin{array}{l}\frac{c}{\sqrt{0}} \\
\text { O } \\
\underline{0}\end{array}$ & 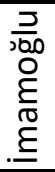 & 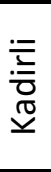 & 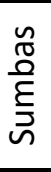 & 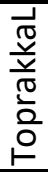 & 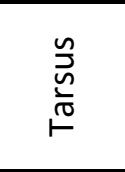 & 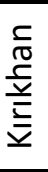 & $\begin{array}{l}\stackrel{\vec{J}}{\bar{\varepsilon}} \\
\stackrel{\underline{\partial}}{\vec{\partial}}\end{array}$ & 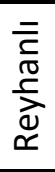 & 일 \\
\hline Deltocephalinae & & & & & & & & & & & & & \\
\hline Cicadulina bipunctella (Matsumura, 1908) & + & + & + & + & + & + & + & + & + & + & + & + & + \\
\hline Circulifer haematoceps (Mulsant et Rey,1855) & + & + & & + & + & + & + & + & + & + & + & + & \\
\hline Doraturopsis heros (Melichar, 1902) & & & & & & & & & & & & + & \\
\hline Euscelidius mundus (Haupt, 1927) & & & & & & & & & + & & & & \\
\hline Euscelidius schenckii (Kirschbaum, 1868) & & & & & & & & + & & & & & \\
\hline Euscelis incisus (Kirschbaum, 1858) & & & & + & & & + & + & & & & & \\
\hline Euscelis lineolatus ( Brulle,1832) & & & & & & + & & & & & & & \\
\hline Exitianus capicola ( Stal,1855) & + & & + & + & + & + & + & & + & + & & + & + \\
\hline Fieberiella florii (Stal,1864) & & & & & + & & + & & & & & & \\
\hline Macrosteles quadripunctulatus (Kirschbaum, 1868) & + & + & & + & + & + & + & + & + & & + & + & + \\
\hline Neoaliturus fenestratus (Herrich-Schäeffer,1834) & & & & & + & + & & & & & & & \\
\hline Neoaliturus opacipennis(Lethierry,1876) & + & & + & + & + & + & + & & + & & + & + & \\
\hline Psammotettix cerinus (Lindberg, 1948) & + & & & & + & & & & & & & & \\
\hline Psammotettix provincialis (Ribaut, 1925) & + & + & + & + & + & + & + & + & + & + & + & + & + \\
\hline Psammotettix striatus (Linnaeus, 1758) & + & + & + & + & + & + & + & + & + & + & + & + & + \\
\hline Recilia schmidtgeni (Wagner, 1939) & & & & & + & & & & + & & & & \\
\hline Thamnotettix zelleri (Kirschbaum, 1868) & & & + & & & & & + & & & & & \\
\hline
\end{tabular}

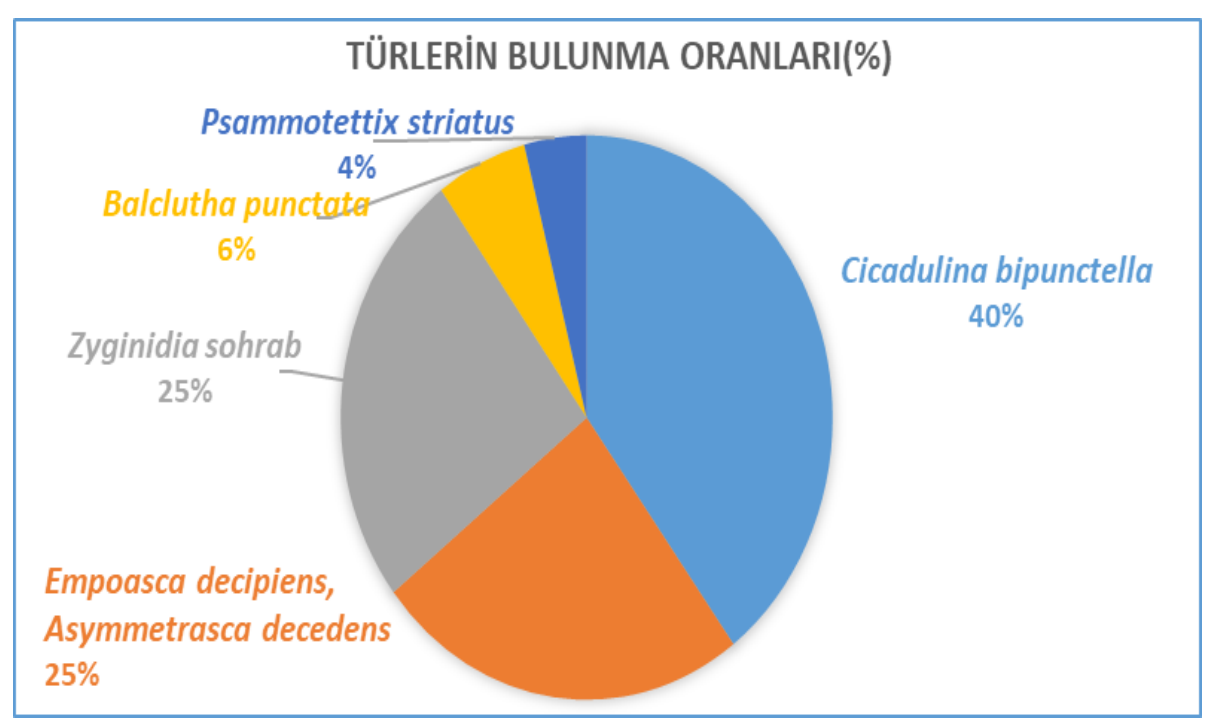

Şekil 1. Doğu Akdeniz Bölgesi'nde I. ve II ürün mısırda 2013-2014 yıllarında yaygın olan türlerin bulunma oranları (\%) Figure 1. Frequencies of common Cicadellidae species (\%) in the first and second crop maize in the Eastern Mediterranean Region in 2013-2014. 
Toplanan türler içerisinde Şekil 1'de de verildiği gibi en yaygın tür olarak $C$. bipuntella (\% 40 ) bulunmuş olup bunu $Z$. Sohrab, E. decipiens ve $A$. decedens (\% 25), $B$. punctata (\% 6) ve $P$. striatus (\% 4) izlemektedir. Bu türlerin potansiyel virüs ve virüs benzeri hastalıkların vektörü olmaları nedeniyle bunların önemleri daha da artmaktadır.

Doğu Akdeniz Bölgesi ana ve ikinci ürün mısır ekiliş alanlarında tespit edilen yaprakpiresi türleri taksonomik sırayla aşağıda verilmiştir.

Altfamilya: Agalliinae

Anaceratagallia laevis (Ribaut, 1935)

İncelenen materyal: Adana (Yüreğir, Seyhan, İmamoğlu, Ceyhan) 14, Osmaniye (Kadirli, Sumbas, Toprakkal) 9, Mersin (Tarsus) 3 ve Hatay'da (Kırıkhan, Reyhanlı) 5 olmak üzere toplam 31 ergin bulunmuştur.

\section{Anaceratagallia ribauti (Ossiannilson, 1938)}

Incelenen materyal: Adana (Karataş, Seyhan, Kozan ve İmamoğlu)'da 10, Osmaniye (Toprakkale, Sumbas, Kadirli)'de 7, Mersin (Tarsus)'de 1 ve Hatay (Kırıkhan, Reyhanlı, Kumlu)'da 8 olmak üzere bölgenin tamamında toplam 26 ergin toplanmıştır.

Altfamilya: Dorycephalinae

Eupelix cuspidata (Fabricus, 1779)

Incelenen materyal: Hatay (Reyhanlı) 1 ergin bulunmuştur.

Altfamilya: Hecalinae

Parabolocratus (Hecalus) storai (Lindberg, 1936)

İncelenen Materyal: Birinci ürün mısırda olgunlaşma döneminde Hatay ili Reyhanlı ilçesi Çakırtepe köyünde 1 adet ergin bulunmuştur.

Altfamilya: Typhlocybinae

Asymmetrasca decedens (Paoli, 1932)

Incelenen Materyal: Asymmetrasca decedens birinci ve ikinci ürün mısır alanlarında örneklemelerin yapıldığı tarlaların genelinde yetişme periyotları boyunca bulunduğu tespit edilmiştir. Morfolojik ayrım yapılamadığından Empoasca decipiens ile birlikte değerlendirilmiştir. Toplam 5.497 ergin elde edilmiştir.

\section{Asymmetropteryx pictilis (Stal, 1853)}

Incelenen materyal: Asymmetropteryx pictilis birinci ve ikinci ürün mısır alanlarında örneklemelerin yapıldığı tarlaların çoğunda erginleri elde edilmiştir. Türkiye'de ilk defa bu çalışmayla belirlenmiştir

Empoasca decipiens (Poali, 1930)

İncelenen materyal: Birinci ve ikinci ürün mısırda örnekleme yapılan bütün alanlarda yetişme periyodu boyunca bulunmuştur. Asymmetrasca decedens ile birlikte toplam 5.497 ergin elde edilmiştir.

Empoasca (Empoasca) vitis (Göthe,1875)

İncelenen materyal: birinci ve ikinci ürün mısırda örnekleme yapılan alanlarda bulunmuştur. E. decipiens ve $A$. decedens türleri için toplanan örneklerin bir kısmında $E$. vitis türü belirlenmiştir.

\section{Zyginidia flammigera (Geoffroy, 1785)}

Incelenen materyal: Mersin (Tarsus, )'de 2 ve Hatay (Reyhanlı )'da 5 olmak üzere toplam 7 birey bulunmuştur. Mersin ve Hatay illeri için ilk kayıttır.

Zyginidia sohrab (Zachvatkin, 1947)

İncelenen materyal: Birinci ve ikinci ürün mısırda örnekleme yapılan tarlalarda üç fenolojik dönemde toplanmıs ve toplam 5.719 ergin elde edilmiştir.

Altfamilya: Deltocephalinae

Allygus provincialis (Ferrari 1882)

Türkiye'deki yayılışı:

İncelenen materyal: Adana (İmamoğlu)'da 2 adet ergin bulunmuştur. Türkiye'de herhangi bir kayıt bulunamamıştır.

Balclutha hebe (Kirkaldy, 1906)

Incelenen materyal: Doğu Akdeniz Bölgesinde birinci ve ikinci ürün mısır ekiliş alanlarında 716 ergin toplanmıştır. Balclutha punctata (Fabricus, 1775)

Incelenen materyal: Çalışmaların yürütüldüğü Adana, Osmanye, Hatay ve Mersin illerinde birinci ürün mısırda yoğunluk düşük seviyede seyrederken ikinci üründe ise ekilişten yaklaşık bir ay sonra çıkmaya başladığı ve hasada kadar yoğun olarak bulunduğu gözlenmiştir. Yapılan sürveylerde toplam 1.340 ergin toplanmıştır.

Chiasmus conspurcatus (Perris, 1857)

İncelenen materyal: Adana (Karataş)'da 1 ergin elde edilmiştir.

\section{Cicadula (Cyperana) intermedia (Boheman, 1845)}

Incelenen materyal: Adana ( Kozan)'da 4 ergin elde edilmiştir. Ülkemizde kaydı bulunamamıştır.

Cicadulina bipunctella (Matsumura, 1908)

İncelenen materyal: Adana, Mersin, Osmaniye ve Hatay illerinde çalışmalarının yürütüldüğü ana ve ikinci ürün mısır tarlalarında fenolojik dönemlerin üçünde yoğun görülen zararlının 8.918 adet ergini yakalanmıştır.

Circulifer haematoceps (Mulsant ve Rey, 1855)

Incelenen materyal: Doğu Akdeniz Bölgesinde sürvey yapılan illerin tamamında toplam 86 adet birey elde edilmiştir.

\section{Doraturopsis heros (Melichar, 1902)}

Incelenen materyal: Hatay (Reyhanlı)'da 1 ergin bulunmuştur.

Euscelidius mundus (Haupt,1927)

İncelenen materyal: Mersin (Tarsus) 1 ergin elde edilmiştir.

Euscelidius schenckii (Kirschbaum, 1868)

Incelenen materyal: Osmaniye (Merkez)'de toplam 4 birey toplanmıştır.

Euscelis (Plebejus) incisus (Kirschbaum, 1858) 
İncelenen materyal: Osmaniye (Toprakkale, Sumbas)'de 3 ve Adana (Kozan)'da 4 olmak üzere toplam 7 ergin elde edilmiştir.

\section{Euscelis lineolatus (Brulle,1832)}

İncelenen materyal: Osmaniye (Kadirli)'de sadece 1 ergin bulunmuştur.

Exitianus (Taeniaticeps) capicola (Stal, 1855)

İncelenen materyal: Adana, Osmaniye, Mersin ve Hatay illerinde örnekleme yapılan tarlalarda toplam 54 ergin toplanmıştır.

\section{Fieberiella florii (Stal,1864)}

İncelenen materyal: Adana (Ceyhan)'da 1, Osmaniye (Sumbas)'de 1 olmak üzere toplam 2 ergin bulunmuştur. Macrosteles quadripunctulatus (Kirschbaum, 1868) İncelenen materyal: Ana ve ikinci ürün mısır ekim alanlarında çalışmaların yürütüldüğü bölge illerinin hepsinde bulunmuş ve toplam 189 ergin sayılmıştır.

Neoaliturus fenestratus (Herrich-Schäeffer, 1834) İncelenen materyal: Adana (İmamoğlu)'da 2, Osmaniye (Kadirli)'de 3 olmak üzere toplam 5 ergin bulunmuştur. Neoaliturus (Circulifer) opacipennis (Lethierry,1876) İncelenen materyal: Doğu Akdeniz Bölgesindeki 4 ilde toplam 47 ergin sayılmıştır.

\section{Psammotettix cerinus (Lindberg, 1948)}

İncelenen materyal: Adana (Ceyhan-1; Karataş-1; İmamoğlu-2)'da toplam 4 birey bulunmuştur.

\section{Psammotettix provincialis (Ribaut, 1925)}

İncelenen materyal: Sürvey yapılan illerin tamamında bulunmuştur. Bu türün $P$. striatus'la morfolojik olarak benzerlik olduğundan toplanan örneklerden her yıl için 20 erkek bireyin genital preparasyonları yapılmıştır. İki yılın ortalamasında \%35 $P$. provincialis, \%65'i ise $P$. striatus çıkmıştır. Böylece toplanan 1.410 bireyden $494^{\prime}$ ü $P$. provincialis olarak belirlenmiştir.

\section{Psammotettix striatus (Linnaeus, 1758)}

İncelenen materyal: Ana ve ikinci ürün mısırda sürvey yapılan illerin tamamında ve toplam 916 ergin elde edilmiştir.

\section{Recilia schmidtgeni (Wagner, 1939)}

Incelenen materyal: Adana (İmamoğlu)'da 3, Mersin (Tarsus)'de 2 olmak üzere toplam 5 ergin bulunmuştur.

\section{Thamnotettix zelleri (Kirschbaum, 1868)}

İncelenen materyal: Adana (Salbaşı)'da 12, Osmaniye (Merkez)'de 6 olmak üzere toplam 18 ergin toplanmıştır. Teşhis edilen türler dışında üç türün örneklerinde erkek birey bulunmadığından sadece dişi bireylerden cins düzeyinde tanılanmıştır. Türlerden, Empoasca sp., Adana (30.09.2013-3)'da, Euscelidius sp. Osmaniye (06.05.2013-4)'de ve Zyginella sp. ise Osmaniye (24.04.2014-1)'de örneklenmiştir. Ayrıca üç örnekte ise sadece birer erkek ergin bulunduğundan teşhisleri cins düzeyinde yapılmıştır. Toplandığı yöreler; Eupteryx sp.
Hatay (30.04.2013-1)'da, Eupteryx sp. Adana (03.06.2013-1)'da ve Doratropsis sp. Osmaniye (06.05.2013-1)'de elde edilmiştir. Toplam 6 tür cins düzeyinde tanılanmıştır.

Sürvey yapılan tarlaların çevresinde genellikle pamuk ile mısır tarlaları görülmüştür. Bazı tarlaların kenarlarında; turunçgil bahçeleri, sebze, ayçiçeği, yerfıstığı ve buğday gibi kültür bitkileri yer almıştır.

Yaprakpiresi türlerinin belirlendiği tarlalarda; Amaranthus retroflexus L., Amaranthus albus L., Chorozophora tinctoria Rafin, Convolvulus arvensis L., Corchorus olitorus L, Euphorbia nutans Lag., Euphorbia serpens Kunth, Hibiscus trionum L., Physalis angulata L., Portulaca oleracea L., Prosopis farcta (Banks. and Sol.) J.F. Macbride, Solanum nigrum L., Tribulus terrestris L, Xanthium strumarium L., Heliotropium europaeum L., Datura stromonium L., Cynodon dactylon (L.) Pers., Cyperus rotundus L., Echinochloa colonum (L.) Link., Setaria verticillata (L.) P. Beauv., Sorghum halepense (L.) Pers., Digitaria sanguinalis (L.) Scop. ve Echinochloa crusgalli (L.) P. Beauv. yabancı ot türleri tespit edilmiştir. Sürvey yapılan bütün tarlalarda en fazla örnek toplanan C. bipunctella ile Z. sohrab türlerinin Allium sp., Avena sp., Chenopodium sp., Brassica sp., Daucus sp., Malva sp., Sonchus sp., Vicia sp., Xanthium sp., A. retroflexus, Arachis hypogaea L., Cynodon dactylon, C. rotundus, Gossypium hirsitum L., Oryza sativa L., Polygonum aviculare L., P. oleracea, Prunus persica (L.) Batsch., Raphanus raphanistrum L., Setaria glauca (L.) P. Beauv., S. nigrum, S. halepense, Spinacia oleracea L. ve Zea mays L. bitkilerinde tespit edildiği bildirilmiştir (Mutlu ve Sertkaya 2008a,b; Mutlu ve ark.2016)

Polifag olan $A$. decedens ve $E$. decipiens türleri daha çok geniş yapraklı ve yoğun yabancı ot ile bulaşık mısır tarlalarında erginleri elde edilmiştir. Önemli konukçuları arasında; Amaranthus sp., Avena sp., Citrus spp., Cyperus sp., Datura sp., Daucus sp., Granium sp., Malva sp, Xanthium sp., Beta vulgaris L., C. dactylon, G. hirsitum, Medicago sativa L., Nicotiana tabacum L., O. sativa, $P$. oleracea, Prunus domestica L., S. glauca, S. nigrum, S. halepense, Vitis vinifera L. ve $Z$. mays bitkileri bildirilmiştir (Lodos ve Kalkandelen, 1983; Başpınar ve Uygun, 1991a; Başpınar ve Öncüer, 2000).

Başpınar ve Uygun (1991b), B. punctata ve B. hebe türlerinin $C$. dactylon $P$. oleracea, $S$. halepense, Cyperus sp., Xanthium sp, çayır ve Cyperaceae familyasının türleri üzerinde bulunduğunu bildirmiştir. $P$. cerinus, $P$. provincialis ve $P$. striatus'un mısır dışında Chenopodium sp., C. dactylon, Malva sylvestris L., P. oleracea, $S$. halepense ve Cyperus sp. adlı yabancı otların da konukçu olduğu belirlenmiştir (Mutlu ve Sertkaya, 2008a,b). 
Çalışmada sınırlı sayıda ergini elde edilen A. laevis, $A$. ribauti, $D$. heros, $E$. lineolatus ve $F$. florii türlerinin genellikle makilik ve çayırlık alanlarda bitkisel besinlerle beslendiğini ve bol miktarda bulunduğunu ve ekonomik önemde olmadığını Önder ve ark. (2011) bildirmişlerdir. Sonuç olarak, Doğu Akdeniz Bölgesi illeri birinci ve ikinci ürün mısır ekili alanlarda, Cicadellidae (Hemiptera) familyasına bağlı toplam 32 yaprakpiresi türü tespit edilmiştir. Belirlenen türlerden ikisi Agallinae, biri Dorycephalinae, biri Hecalinae, beşi Typhlocybinae, 22'si ise Deltocephalinae altfamilyalarına aittir.

C. bipunctella, Z. sohrab, $A$. decedens, $E$. decipiens, ve $B$. punctata vejetasyon boyunca yaygın ve yoğun türler olarak belirlenmiştir. A. ribauti, A. pictilis, E. vitis, $P$. striatus, $P$. provincialis, $B$. hebe, $C$. haematoceps, $E$. (taeniaticeps) capicola, $M$. quadripunctulatus, $N$.(Circulifer) opacipennis türleri çalışmanın yürütüldüğü tüm alanlarda bulunmuştur. Hatay'da değişik sebze alanlarında yaptıkları örneklemelerde Kılıç ve Sertkaya (2019) 18 tür, aynı ilde mısır, pamuk, sebze alanlarında ışık tuzağıyla yapılan diğer bir çalışmada ise 30 Cicadellidae türü tespit edilmiştir (Kaya ve Başpınar, 2019). Ege Bölgesinde mısırda 17 tür (Yılmaz ve ark., 2009), Diyarbakır'da ikinci ürün mısırda ise Cicadellidae familyasına bağlı 20 türün bulunduğu bildirilmiştir (Mutlu ve ark., 2008b).

Türlerden $A$. pictilis, $A$. provincialis, ve $C$. intermedia Türkiye faunası için yeni kayıt niteliğindedir. $P$. storai ve $D$.heros türleri Hatay için yeni kayıttır. E. schenckii ve $E$. lineolatus türleri Osmaniye için F. florii türü ise Adana ve Osmaniye için yeni kayıt olarak yazılmıştır.

Morfolojik olarak aynı grupta yer alan A. pictilis, E. vitis, $A$. decedens ve $E$. decipiens türleri arasında $A$. decedens ve $E$. decipiens baskın ancak uygun koşullar oluştuğunda ileriki dönemlerde diğer iki türünde yüksek popülasyon oluşturabilecekleri düşünülmektedir.

Bölge illerinde birinci ve ikinci ürün mısırda en fazla örnek elde edilen $C$. bipunctella'nın cins özelliğinden virüs vektörü olması, beslenme sırasında salgıladığı kimyasallarla; damarlarda şişkinlik ve ur, büyümede bodurluğa neden olmaktadır. Türün ileriki yıllarda bölgede mısır üretim alanlarında ekonomik önemde verim kayıplarına neden olabileceğinden mücadelesine yönelik çalışmaların yürütülmesi önerilmektedir. Ayrıca virüs vektörü olarak belirlenen $C$. haematoceps, $N$. fenestratus, $P$. striatus türlerininde popülasyon gelişimlerinin ve ürüne olan etkileri ile mücadele olanaklarının araştırılması uygun olacaktır.

\section{ÖZET}

Amaç: Bu çalışmada Doğu Akdeniz Bölgesindeki Adana,
Osmaniye, Mersin, Hatay illerinde birinci ve ikinci ürün mısır üretim alanlarında bulunan Cicadellidae familyasına ait zararlı türlerini belirlemektir.

Yöntem ve Bulgular: Bu çalışma 2013-2014 yıllarında Doğu Akdeniz Bölgesinde yer alan Adana, Mersin, Osmaniye ve Hatay illerindeki birinci ve ikinci ürün mısır ekiliş alanlarında yürütülmüştür. Örneklemeler her mısır tarlasının farklı beş noktasında vakumlu böcek toplama (D-Vac) aleti ile gerçekleştirilmiş ve bitkiler 60'ar saniye süre ile emilmiştir. Mısır bitkisinin birinci ve ikinci ürün ekiliş alanlarında vejetatif, generatif ve olgunlaşma olmak üzere üç fenolojik dönemde toplam 236 tarlada yaprakpireleri örneklenmiştir.

Genel Yorum: Çalışma sonunda, Cicadellidae (Hemiptera) familyasından 5 alt familyaya bağlı 32 tür tespit edilmiştir. Türlerden ikisi Agalliinae, biri Dorycephalinae, biri Hecalinae, altısı Typhlocybinae ve 22 adedi ise Deltocephalinae altfamilyalarına aittir. illere göre türlerin dağılımı Adana'da üç altfamilyaya ait 23 tür, Osmaniye'de üç altfamilyaya ait 22 tür, Mersin'de üç altfamilyaya ait 19 tür ve Hatay'da beş altfamilyaya ait 20 tür saptanmıştır.

Çalışmanın Önemi ve Etkisi: Çalışmada belirlenen Cicadellidae türlerinden, Asymmetropteryx pictilis (Stal, 1853), Allygus provincialis (Ferrari 1882) ve Cicadula (Cyperana) intermedia (Boheman,1845) türleri Türkiye faunası için ilk kayıttır. Bölgede en fazla örnek toplanan Cicadulina bipunctella'nın virüs vektörü olması, beslenme sırasında salgıladığı kimyasal salgıyla damarlarda şişkinlik, ur, büyümede bodurluk yapması nedeniyle türün ileriki yıllarda mısırda ekonomik önemde verim kayıplarına neden olabileceği öngörülmektedir. C. bipunctella ile birlikte virüs vektörü olarak bilinen Circulifer haematoceps, Neoaliturus fenestratus, Psammotettix striatus türlerininde takip edilmesi ve sonraki yıllarda olası popülasyonlarına karşı mücadele olanaklarının araştırılması gerekir.

Anahtar Kelimeler: Mısır, yaprakpiresi türleri, vektör, vakumlu böcek toplama aleti, Doğu Akdeniz Bölgesi.

\section{TEŞEKKÜR}

Bu çalışma birinci yazarın Yüksek Lisans tezinin bir bölümüdür. Tarımsal Araştırmalar ve Politikalar Genel Müdürlüğü tarafından TAGEM-BS-13/12-03/01-02 nolu projeyle desteklenmiştir. Çalışma Türkiye VI. Bitki Koruma Kongresinde poster özet olarak sunulmuştur. Cicadellidae familyasının 2013 yılı örneklerini teşhis eden; Prof. Dr. Hüseyin BAŞPINAR'a, 2014 yılı ile 2013 yılından kalan örnekleri tanılayan Prof. Dr. Ünal ZEYBEKOĞLU'na ve Asymmetresca decedens ile 
Empoasca decipiens türlerini tanılayan Prof. Dr. Şaban GÜÇLÜ’ye teşekkür ederiz.

\section{ÇIKAR ÇATIŞMA BEYANI}

Yazarlar çalışma konusunda çıkar çatışmasının olmadığını beyan eder.

\section{ARAŞTIRMACILARIN KATKI ORANI BEYANI}

Yazarlar çalışmaya eşit oranda katkı sağlamış olduklarını beyan eder.

\section{KAYNAKLAR}

Alaoğlu Ö, Ercan B, Sade B, Soylu S, Öztemiz S, Patla Ç, Güneş A, Fidan H, Uysal M, Tezel M (2007) Zyginidia sohrab Zachvatkin (Hemiptera: Cicadellidae)'ın misır (Zea mays L) bitkisinde popülasyon gelişimi ile yoğunluğunun verim ve verim öğeleri üzerine etkileri. Bitkisel Araştırma Dergisi 1: 1-7.

Anonim (2013) Oleo-Mac Bw300 marka yaprak toplama ve üfleme makinesi. Anadolu Ticaret. San. Tic. Lim. Şir., http://www.anadolutic.com.tr/Adana.

Anonim (2018) Konularına göre istatistikler, Bitkisel üretim istatistikleri. www.tuik.gov.tr/ Türkiye İstatistik Kurumu. Devlet mah. Necatibey cad. no. 114 06650, Çankaya/ Ankara.

Başpınar H, Uygun N, (1991a) Doğu Akdeniz Bölgesi turunçgil bahçelerindek Cicadellidae türleri üzerinde faunistik ve sistematik çalışmalar II. Türk. Entomol. Derg. 15(3): 157-172.

Başpınar H, Uygun N, (1991b) Doğu Akdeniz Bölgesi turunçgil bahçelerindeki Cicadellidae türleri üzerinde faunistik ve sistematik çalışmalar III. Türk. Entomol. Derg. 15(4): 203-222.

Başpınar H (1994) Some obvervations on dominant structure and population changes of Asymmetrasca decedens (Paoli) and Empoasca decipiens Paoli (Hem.,Cicadellidae) on different crops in Adana. Türk. Entomol. Derg. 18(2): 71-76.

Başpınar H, Öncüer C (2000) Aydın ilinde meyve bahçelerinde Cicadellidae (Homoptera) türlerinin saptanması. Türkiye IV. Entomoloji Kongresi Bildirileri, Aydın, 409-419.

Bushing RW, Burton VF (1974) Leafhopper damage to silage corn in California. J. Econ. Entomol. 67: 656658.

Kaya K, Başpınar H (2019) Cicadellidae family species obtained from light trap in Hatay province and their population densities. MKU. Tar. Bil. Derg. 24(1): 3136.
Kılıç M, Sertkaya E (2019) Determination of Cicadellidae, Cixiidae and Delphacidae (Hemiptera) pest species on the vegetables of Solanaceae family in Hatay province of Turkey. MKU. Tar. Bil. Derg. 24(3): 217-231.

Lodos N (1981) Maize pests ve their importance in Turkey. EPPO Bull. 11(2): 87-89.

Lodos N, Kalkandelen A (1983) Preliminary list of Auchenorrhyncha with notes on distribution ve importance of species in Turkey, XII. Family Cicadellidae: Typhlocybinae: Empoascini. Türk. Bit. Kor. Derg. 7: 153-165.

Mutlu Ç, Sertkaya E, Güçlü Ş (2008a) Diyarbakır ili ikinci ürün mısır alanlarında Cicadellidae (Homoptera) familyasına bağlı önemli türlerin populasyon değişimleri. Türk. Entomol. Derg. 32(1): 21-32.

Mutlu Ç, Sertkaya E, Güçlü Ş (2008b) Diyarbakır ili ikinci ürün mısır alanlarında bulunan Cicadellidae (Homoptera) türleri ve yayılış alanları. Türk. Entomol. Derg. 32(4): 281-301.

Mutlu Ç, Sertkaya E (2016) Biology of the leafhopper, Zyginidia sohrab Zachvatkin, on corn under laboratory conditions. J. Entomol. Zool. Stud. 4(4): 401-406.

Mutlu Ç, Duman M, Karaca V, Bayram Y, Süer, I E (2016) Karacadağ çeltiğinde Cicadellidae, Cixiidae ve Delphacidae (Hemiptera) türleri ile bunların popülasyonuna yabancıotların etkisi. Türk. Entomol Bült. 6(4): 279-289.

Nault LR (1980) Maize bushy stunt ve corn stunt: A comparison of disease symptoms, pathogen host ranges, ve vectors. Phytopathology 70: 659-662.

Oman PW (1949) Nearctic Leafhoppers (Homoptera: Cicadellidae), a generic classification ve check list. Mem. Entomol. Soc. Washington, 3: 1-253.

Önder F, Tezcan S, Karsavuran Y, Zeybekoğlu Ü (2011) Türkiye Cicadomorpha, Fulgoromorpha ve Sternorrhyncha (Insecta:Hemiptera) Kataloğu (Kitap). http://www.entomoloji.org.tr/ .

Seifers DL, Harvey TL (1989) Effect of carbofuran on transmission of maize dwarf mozaic virus in sorgum mechanically inoculated by the aphid, Schzaphis graminum. Plant Dis. 73: 61-63.

Yılmaz E, Karsavuran Y, Zeybekoğlu Ü (2009) Aydın, İzmir ve Manisa illeri mısır alanlarında belirlenen Cixiidae ve Delphacidae (Homoptera) familyalarına bağı türler üzerinde araştırmalar. Türk. Entomol. Derg. 33(1): 63-71. 